\title{
Review on the Technology and Application of Lead Contaminated Soil Remediation
}

\author{
Lan Lina ${ }^{1,2}$, Sun Xiaojie $e^{1,2, \star}$ \\ ${ }^{1}$ Guangxi Key Laboratory of Environmental Pollution Control Theory and Technology, Guilin University of Technology, Guilin 541004, China \\ ${ }^{2}$ Guangxi Collaborative Innovation Center for Water Pollution Control and Water Safety in Karst Area, Guilin University of Technology, \\ Guilin 541004, China
}

\begin{abstract}
With the acceleration of industrialization and urbanization, and lead pollution of soil area in our country, blood lead happened frequently in recent years, the lead pollution of soil is a problem that cannot be ignored.This paper briefly illustrates the soil lead pollution present situation, summarizes some soil lead pollution repair technology, and looking to the future development trend of soil lead pollution repair technology.
\end{abstract}

\section{Introduction}

With the acceleration of urbanization and industrialization process, soil heavy metal pollution has become a global concern, industrial emissions, sewage irrigation, living garbage dumps,etc. ${ }^{[1-2]}$, can cause heavy metal pollution. Lead is a heavy metal contaminated soil widely distributed, with a strong accumulation of environmental contaminants. Natural sources of lead in the soil is weathered rock minerals. Over the years, even though people on three wastes (waste gas, waste water, waste) emissions has taken strict control measures, however, due to the frequent human activities, along with mining, metal smelting and processing, IT manufacturing, sewage discharge, sewage irrigation, as well as the use of sludge and leaded gasoline, lead has become one of the main elements of soil pollution. The soil has not only affected the soil microbial, enzyme activity and physical and chemical properties ${ }^{[3]}$, but also the two pollution of surface water and groundwater, and through the food chain harm to human health. Excessive accumulation of lead can cause human body's nervous system, hematopoietic system, digestive system and reproductive system disorders, in particular, the most damaging to children. Thus, contamination of soil lead in recent years has become one of the main directions of heavy metal pollution research questions. To solve the problem of lead contamination, on the one hand, we should reduce pollution sources; On the other hand, we will have to repair the contaminated soil. In this paper, lead-contaminated soil remediation techniques are reviewed to provide a basis for the restoration of lead contamination of soil research and practice.

\section{Lead pollution in soil}

\subsection{Background value of lead in soil}

The average background value of lead in soil was 26 $\mathrm{mg} / \mathrm{kg}^{[4]}$, lead content in soil was $2 \sim 200 \mathrm{mg} / \mathrm{kg}$, and the average content was $13 \sim 42 \mathrm{mg} / \mathrm{kg}$, In general, the lead content of the city far and the non contaminated soil $10 \sim 30 \mathrm{mg} / \mathrm{kg}$, city road on both sides, as well as the low pollution area of soil $30 \sim 100 \mathrm{mg} / \mathrm{kg}$, lead and zinc mine enterprise pollution of the soil can exceed $10000 \mathrm{mg} / \mathrm{kg}$, leaded gasoline lead 400 1000 mg/kg, which means that the vehicle exhaust gas contains a lot of lead, accumulated in the road on both sides of the soil. In addition, the lead content of some suburban sewage irrigation district and orchard soil is also higher ${ }^{[5]}$.

\subsection{Sources of lead pollution}

\subsubsection{Waste gas}

Lead mainly from two aspects of the atmosphere, on the one hand is the natural source, refers to the volcanic eruption smoke, dust particles, forest fire smoke and sea salt aerosol and other natural phenomena released into the environment of lead. On the other hand is human activities, including lead mining, smelting, battery industry, glass manufacturing, powder metallurgy and fuel oil, fuel coal combustion gas.

\subsubsection{Industrial waste water irrigation}

Lack of water resources, so that the sewage has become an important part of irrigation water. Lead, mercury, cadmium and other heavy metal elements in the soil can be enriched in the soil and have the characteristics of difficult degradation, strong toxicity and so on. Under normal circumstances, the lead content of soil in sewage irrigation area increases with the increase of lead ion concentration in waste water, and the pollution degree increases with the increase of the sewage irrigation time ${ }^{[6]}$.

\subsubsection{Lead pollution in soil}

At present, average annual emissions of lead is about $500104 \mathrm{t}$ all over the world. According to statistics, China has about $1.3104 \mathrm{hm}^{2}$ of arable land by lead and other heavy metal pollution, resulting in grain output of 1000 104t. Lead pollution in soil is very common in the city, among them, the commercial district and the industrial and mining areas of soil lead pollution is relatively heavy, but relatively small areas of soil lead pollution in relatively small areas of scenic areas and agricultural areas. In addition, on both sides of the road, soil lead pollution is very obvious, showing a certain regularity. 
For example,extending along both sides of the highway on the zonal distribution, pollution is mainly concentrated in the road area less than $200 \mathrm{~m}$, lead content in soil surface $30 \mathrm{~cm}$ was higher, down rapidly, in the horizontal range from near the highway to the far away from the road was Gauss attenuation ${ }^{[7]}$.

\section{Lead contaminated soil remediation technology}

At present, the soil remediation technology of heavy metal contaminated soil is mainly divided into physical, chemical and biological repair, and joint repair and so on ${ }^{[8]}$. Physical repair method can be divided into modified method, isolation embedding method and electrokinetic remediation method. Chemical restoration can be divided into flushing/washing complex method and the soil amendments method. Bioremediation can be divided into phytoremediation and microbial remediation ${ }^{[9]}$.

\subsection{Physical remediation}

(1) Modified method. For indigenous is after the removal of contaminated topsoil for new clean soil, use of lead pollution in surface soil properties ${ }^{[10]}$, after removal of surface contamination in soil farming method of activating subsoil or covered in uncontaminated soil. Soil method is by adding a lot of uncontaminated soil to the soil, cover on the surface or mixing, lead concentration decreased, reduce exposure to lead and plant roots, so as to reduce the damage.

(2) The method of isolating the embedded. The isolation method is a method for reducing the lead pollution in the soil and the surrounding environment. Concrete practice is to use steel, cement, etc. in the surrounding areas of pollution and the construction of the wall, and to prevent the pollution of water and leakage of water flow into the surrounding areas. In order to pollute the surrounding soil and groundwater, the leakage coefficient of the wall is less than $10 \sim 12 \mathrm{~cm} / \mathrm{s}$.

(3) Electrokinetic remediation. The concrete measure is to insert the electrode into the water saturated soil, and then pass through the low intensity DC power, lead ion in the electric field direction. Finally, it is enriched by the electrode. The lead is collected by engineering measures to achieve the purpose of removing lead ${ }^{[11]}$. Zhang et $\mathrm{al}^{[12]}$ studies found that the removal rate of pollutants increased with the increase of the recovery time under the action of electric field force, and the removal rate was increased from $13 \%$ to $20 \%$ when the recovery time from 5 day to 15day.

\subsection{Chemical remediation}

(1)Flushing/washing complex method. Flushing/washing complex method is using reagents and lead in soil, the formation of the solubility of lead ions or complex, then with water to flush out pollutants, collect rinse and recycle lead ${ }^{[13]}$. Wang ${ }^{[14]}$ artificial polluted soil as experimental material, through leaching oscillation experiment and soil column leaching experiment study soil adsorption technology of lead contaminated soil, to carry out the screening eluent, finally found the easily biodegradable APG surfactant as eluent. Flushing/washing complex method removal efficiency rapidly, but the high cost, easy to cause secondary pollution.

(2)Amendments method. Amendments method is added chemical substances to the lead contaminated soi, reducing the effectiveness and mobility of lead in the soil, thereby reducing biological toxicity. Research focus mainly on phosphorus repair. Because of soil phosphorus and lead form insoluble lead phosphate compounds, using different cheap phosphorus containing substances carry on in-situ remediation of lead contaminated soil is considered to be the best management measures of lead contaminated soil, attention at home and abroad ${ }^{[15]}$.

\subsection{Biological remediation}

(1)Phytoremediation. Hyperaccumulator is the plants of absorb heavy metals more than the general plant 100 times. Continuous planting on hyperaccumulator on heavy metal contaminated soils, the heavy metal can be transferred out of the soil when the plants were harvested and properly handle, so as to achieve the purposes of pollution control and ecological restoration ${ }^{[16]}$. Phytoremediation can be divided into three types of phytoextraction, phytovolatilization and phytostabilization. Phytoextraction can be divided into continuous plant extraction and induce plant extraction. Cui et $\mathrm{al}^{[17]}$ to enrich data of $\mathrm{Pb}$ toxicity, purify and beautify $\mathrm{Pb}$-contaminated environment, three ornamental flowers were used to determine the absorbing characteristics of $\mathrm{Pb}$ and endurable characteristics with pot-culture experiment. The results showed Tagetes patula had a stronger capability of accumulating $\mathrm{Pb}$ in shoot than that Dahlia pinnata and Ipomoea quamoclit, but had the weakest accumulating ability. Dahlia Pinnata Cav and Tagetes patula exhibited stronger endurance to $\mathrm{Pb}$, which could be used for stable remediation of soil. Wang et al ${ }^{[18]}$ through bonsai simulation test was done to study the influence of EDTA added to $\mathrm{Pb}, \mathrm{Cd}$ and $\mathrm{Pb}-\mathrm{Cd}$ compound contaminated soil on chlorophyll in Chrysanthemum coronarium. Results indicated that highly concentrated EDTA affected the chlorophyll content in Chrysanthemum coronarium, which would cause chlorophyll disarrangement of structure, leaf chlorosis, or even withers completely. In $\mathrm{Pb}$ processing soil, when EDTA added by $2.5 \mathrm{mmol} / \mathrm{kg}$, the content of chlorophyll a, chlorophyll $\mathrm{b}$ and chlorophyll $\mathrm{a}+\mathrm{b}$ in the Chrysanthemum coronarium increased by $38.46 \%$, $32.35 \%$ and $34.48 \%$ respectively, while EDTA increased to $7.5 \mathrm{mmol} / \mathrm{kg}$, the content of chlorophyll a, chlorophyll $\mathrm{b}$ and chlorophyll a+b decreased by $42.31 \%, 35.29 \%$ and $40.23 \%$ respectively. In $\mathrm{Pb}-\mathrm{Cd}$ compound processing soil, EDTA obviously reduced chlorophyll content in the Chrysanthemum coronarium, compared with the separately process. So that: the induction of plant extraction method is more suitable for the repair of low concentration of contaminated soil.
(2)Bioremediation. Bioremediation mainly through 
microbial biochemical reactions to stabilize or clean up the lead in the environment, and it can be divided into two kinds of microorganism immobilization and microbial transformation. Microbe fixed on lead have main three ways of extracellular precipitation, complex extracellular and intracellular accumulation ${ }^{[19]}$. Since microbes have certain affinity for lead and adsorption capacity, toxic metal ions can accumulate in different parts of the cell or bound to the extracellular matrix, or complexed on biopolymers. He et al ${ }^{[20]}$ experimental results show that in all levels of lead pollution, AM fungus, applying manure and combined treatment significantly promote the growth of tobacco, and improve the phosphorus nutrition of tobacco. Wang et al ${ }^{[21]}$ study on bioremediation of $\mathrm{Pb}$ polluted water using calcite precipitating bacterium Pseudomonas stutzeri. Experiment shows that over $97 \%$ of $\mathrm{Pb}$ was efficiently removed by the bacterium due to its co-precipitation with calcium carbonate.

\section{Expectation}

Traditional methods for controlling lead contaminated soil is high cost, exist secondary environmental risks and difficult to widespread used.Phosphorus modifier and induce plant extraction belong to the new soil pollution remediation technology, with the advantages of cheap, easy to operate, etc. It have been successful examples in the international community $^{[22]}$. For mining wasteland or near the factory with high lead content in the soil or may be used phosphorus conditioner fixed, limiting its spread to the surrounding area. For low concentration of lead contaminated soil can be used to induce plant extraction technology, extraction induced by planting enrichment plant, in order to achieve the removal of lead from soil and the utilization value of recovery resources. Bioremediation and phytoremediation technology have broad application prospects. How to optimize the combination of physical-chemical method and bioremediation technology has become the focus and trend of the research on the soil remediation technology of lead contaminated soil in the future.

\section{Acknowledgment}

This work was financially by Guangxi Scientific Experiment Center of Mining, Metallurgy and Environment and The project of high level innovation team and outstanding scholar in Guangxi colleges and universities (002401013001).

\section{Reference}

[1] Zhao S L, Duo L A. Chinese Journal of Environmental Engineering, 5 (2011)

[2] Xie W Y, Fan G S, Zhou H Q, et al. Journal of Agro-Environment Science, 30 (2011)

[3] KHAN K S, XIE Z M, HUANG C Y. Pedosphere, 8 (1998)

[4] Li X Y. Soil Chemistry. (2005)

[5] Wang Z, Shao Z Q. Agricultural Technology \& Equipment, (2010)

[6] T Manios, E I Stentiford, P M illner. ChemospHere, 53 (2003)

[7] Cheng X W. Ground water, 33 (2011)

[8] Zhang $\mathrm{H}$ Y, Liu Y, Li J, et al. SICHUAN ENVIRONMENT, 29 (2010)

[9] Gao W Q, Chen Y F. Nonferrous Metals, 63 (2011)

[10] HASSANIN A. Water Air Soil Pollution, 66 (1993)

[11] PROBSTEIN R, HICKS R. Science, 260 (1993)

[12] Zhang T, Zou H, Wang Y N , et al. Chinese Journal of Environmental Engineering, 7 (2013)

[13] HANSON A, DAVID T, SABATIN A. Transport and remediation of subsurface contaminants. (1992)

[14]Wang D H. Hebei University of Science and Technology, (2013)

[15] Chen S B, Li N, Wang M, et al. Chinese Journal of Eco-Agriculture, 18 (2010)

[16]Liu J W, Zhu H. Guide of Sci-tech Magazine, 34 (2014)

[17] Cui S, Liu Y Y, Sun X J, et al. Hubei Agricultural Sciences, (2014)

[18] Wang X F, Luo X D, Pi Y Q. Environmental Science \& Technology, 34 (2011)

[19]RIDVAN K. European Journal of Soil Biology, 40 (2004)

[20] He Y H, Wang L, Sun D X, et al. Chinese Tobacco Science, 34 (2013)

[21] Wang X H, Zhao C X, Pan X L. EARTH AND ENVIRONMENT, (2015)

[22] Xiao C, Li L, Zha Z Y. Chongqing Technol Business Univ.(Nat Sci Ed), 29 (2012) 